\title{
OPTICALLY CONTROLLED MICROWAVE ATTENUATORS
}

\author{
P. BHUSHAN MITAL \\ Fellow Member IETE, Department of Electronics \& Communication Engg., C.R. State College of \\ Engineering, Murthal (Sonepat), India-131039
}

(Received August 2, 1994; in final form September 7, 1994)

\begin{abstract}
The concept of photoconductivity is utilized in a number of microwave applications such as switches and attenuators. Optically controlled microwave attenuators prove an alternative to the conventional attenuators due to their simplicity, easy of operation, and very narrow ranges of continuously varying attenuation levels available. This paper describes the design of such configurations of optically controlled attenuators on a microstrip line fabricated on a semiconductor substrate.
\end{abstract}

\section{INTRODUCTION}

Attenuators are important components in a microwave system. The conventional attenuators have limitations of small bandwidth, low power handling capability, and less control. The optically controlled attenuators are expected to be free from these shortcomings. These depend on the photoconductivity generated in a high resistivity semiconductor substrate.

When a semiconductor is illuminated by an optical source of an appropriate wavelength, the optical energy is absorbed by the semiconductor, elevating the electrons to the conduction band in mass and, hence, the conductivity of the semiconductor is increased dramatically. The absorption of optical energy is a strong function of wavelength of the illuminating source as shown in Fig. 1A. The absorption coefficient $\alpha$ is given by ${ }^{1}$ as

$\alpha(h f)=\frac{2 \pi g_{x} a_{0}(h f)}{1-\exp \left(-2 \pi g_{x}\right)} ;$ hf $\rangle=E_{g}$

where

$\mathrm{g}_{\mathrm{x}}=\left[\mathrm{R}_{\mathrm{x} 1} /\left(\mathrm{hf}-\mathrm{E}_{\mathrm{g}}\right)\right] 1 / 2$

$\mathrm{R}_{\mathrm{x} 1}=4.2 \mathrm{meV}$

$\alpha_{0}(\mathrm{hf})=(\beta / \mathrm{hf})\left(\mathrm{hf}-\mathrm{E}_{\mathrm{g}}\right) 1 / 2$

$\beta$ : a complex function of wavelength

h: Plank's constant

f: frequency of the optical source 


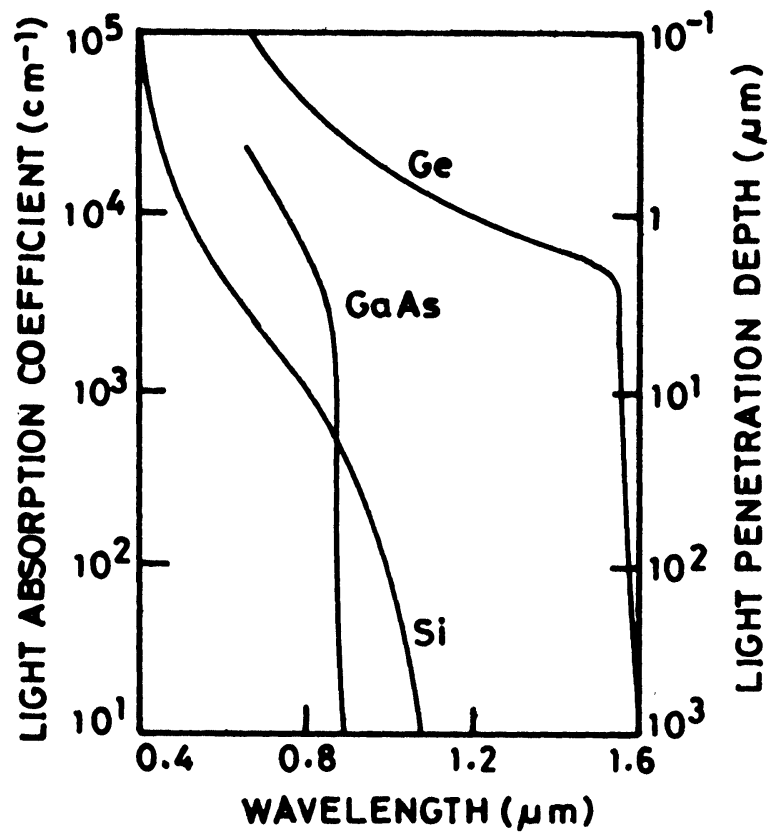

FIGURE 1A Optical absorption coefficient wavelength for silicon germenium and gallium arsenide.

$\mathrm{E}_{\mathrm{g}}$ : bandgap energy

Depending on the absorption coefficient $\alpha$, the conducting plasma can be created up to a certain depth in the semiconductor on illumination. The expression for plasma penetration depth $d_{e}$ is given by ${ }^{2}$ :

$\mathrm{d}_{\mathrm{e}}=\frac{\left[\mathrm{L}_{\mathrm{a}}\left(1+\alpha \mathrm{L}_{\mathrm{a}}\right)+\mathrm{V}_{\mathrm{s}} \mathrm{t}\right]}{\alpha\left(\mathrm{L}_{\mathrm{a}}+\mathrm{V}_{\mathrm{s}} \mathrm{t}\right)} \mathrm{A}^{\mathrm{x}}$

where

$\mathrm{A}=\frac{1}{\alpha \mathrm{L}_{\mathrm{a}}} \frac{\left(\mathrm{aL}_{\mathrm{a}}^{2}+\mathrm{v}_{\mathrm{s}} \mathrm{t}\right)}{\left(\mathrm{L}_{\mathrm{a}}+\mathrm{v}_{\mathrm{s}} \mathrm{t}\right)}$

$\mathrm{x}=\mathrm{L}_{\mathrm{a}} /\left(1-\alpha \mathrm{L}_{\mathrm{a}}\right)$

$\beta=\exp \left(-\mathrm{W} / 2 \mathrm{~L}_{\mathrm{a}}\right)$

$\mathrm{W}=$ dimensions of the illuminated slot

$\alpha=$ optical absorption coefficient

$\mathrm{L}_{\mathrm{a}}=$ ambi-polar diffusion length

$\mathrm{V}_{\mathrm{s}}=$ surface recombination velocity

$\mathrm{t}=$ excess carrier lifetime 
If the penetration depth $d_{e}$ is very small compared to the substrate thickness, then the plasma so created is called the surface plasma. In contrast, if $d_{e}$ is large, then the plasma is called the bulk plasma.

The surface and the bulk plasma can be used to electrically bridge the gap between two conductors (Fig. 1B). This phenomenon is used in optically controlled microwave switches and attenuators.

\section{PRINCIPLE OF THE OPTICALLY CONTROLLED MICROWAVE ATTENUATOR}

The semiconductor material between two conductors can be made photoconducting by optical illumination, creating an equivalent photoconductance. Fig. 2A shows a microstrip line on a semiconducting substrate. If the semiconductor between the two conductors of the microstripline is made photoconducting, this will create shunt conductance between the two conductors. Due to this shunt conductance, some of the incoming microwave power is reflected back and only part of it is transmitted.

We have

$\mathrm{P}_{\mathrm{r}}=\mathrm{g}^{2} \mathrm{P}_{\mathrm{i}}$

$\mathrm{g}=\frac{1 / \mathrm{G}-\mathrm{Z}_{0}}{1 / \mathrm{G}+\mathrm{Z}_{0}}$

G: shunt photoconductance

$\mathrm{Z}_{0}$ : characteristic impedance of the transmission line.

The attenuation is obtained, since the transmitted power is a function of the shunt photoconductance, which can be varied by optical illumination. The equivalent circiut is shown in Fig. 2B.

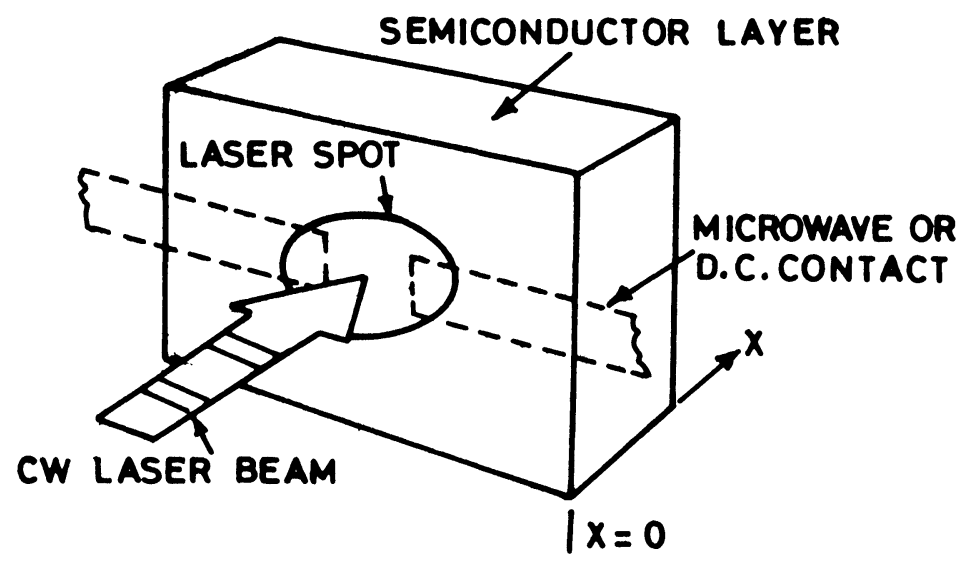

FIGURE 1B Typical arrangement for the optical control of photoconductivity. 


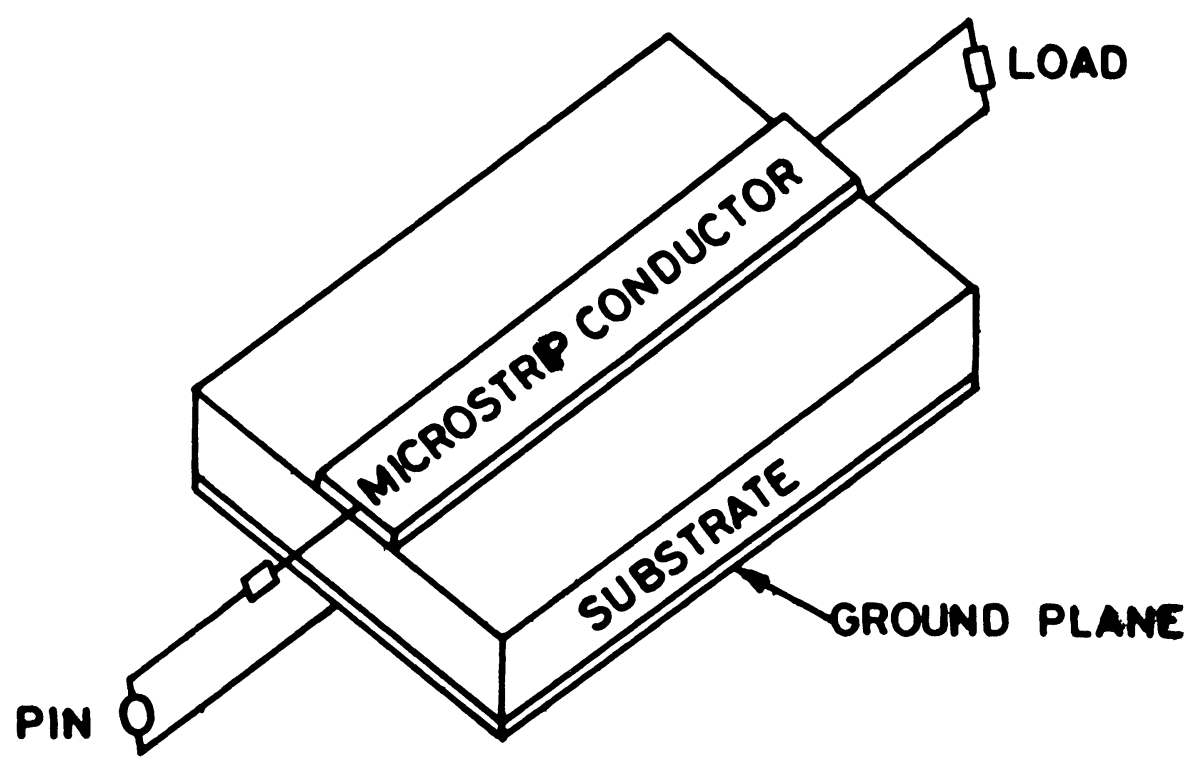

FIGURE 2A Microstripline on semiconducting substrate.

The effective photoconductivity $\sigma_{\mathrm{e}}$, produced by the optical illumination is given by $^{2}$ :

$\sigma_{\mathrm{e}}=\sigma_{\mathrm{m}}\left(\mathrm{W} / 4 \mathrm{~L}_{\mathrm{a}}\right)(1-\beta) 1 / 2\left[\frac{\operatorname{Arth}(1-\beta)}{(1-\beta) 1 / 2}\right]^{-1}$

where

$\sigma_{\mathrm{m}}=\frac{\sigma_{0}}{\left(1-\alpha \mathrm{L}_{\mathrm{a}}\right)} * \beta^{-\mathrm{x}}$

$\sigma_{0}=(\mathrm{q} / \mathrm{hc})\left(\mu_{\mathrm{n}}+\mu_{\mathrm{p}}\right)(1-\mathrm{R}) \alpha \mathrm{S} \mathrm{tP} / \mathrm{A}$

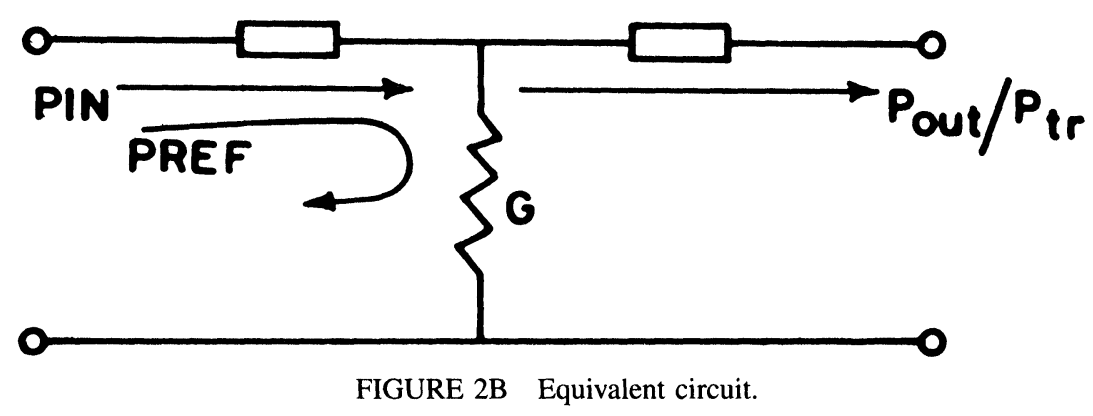


$\mathrm{B}=\frac{1}{\alpha \mathrm{L}_{\mathrm{a}}} \frac{\alpha \mathrm{L}_{\mathrm{a}}^{2}+\mathrm{V}_{\mathrm{s}} \mathrm{t}}{\mathrm{L}_{\mathrm{a}}+\mathrm{v}_{\mathrm{s}} \mathrm{t}}$

$\mathrm{x}=\alpha \mathrm{L}_{\mathrm{a}} /\left(1-\mathrm{aL}_{\mathrm{a}}\right)$

$\beta=\exp \left(-\mathrm{W} / 2 \mathrm{~L}_{\mathrm{a}}\right)$

$\mathrm{W}=$ dimensions of the illuminated slot

$\alpha=$ optical absorption coefficient

$\mathrm{L}_{\mathrm{a}}=$ ambi-polar diffusion length

$\mathrm{v}_{\mathrm{s}}=$ surface recombination velocity

$\mathrm{t}=$ excess carrier lifetime

$\mathrm{R}=$ surface reflectivity

$\mathrm{S}=$ relative spectral response

The photoconductivity is dependent on the optical absorption coefficient and, hence, on the wavelength of the illuminating source. A program was made to obtain values of photoconductivity corresponding to different wavelengths. The results are given in Table 1 and Fig. $3 \mathrm{~A} \& \mathrm{~B}$.

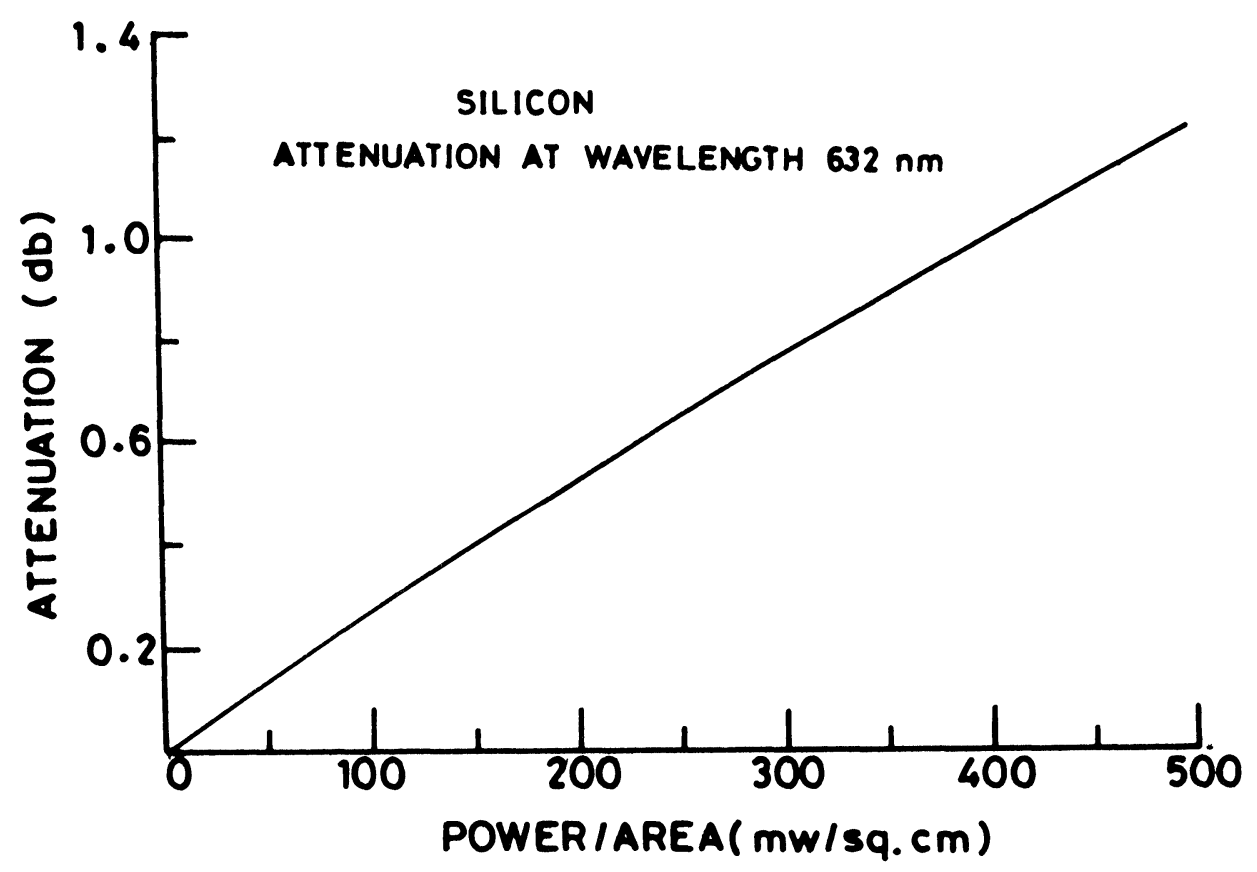

FIGURE 3A Attenuation vs power/area (silicon). 


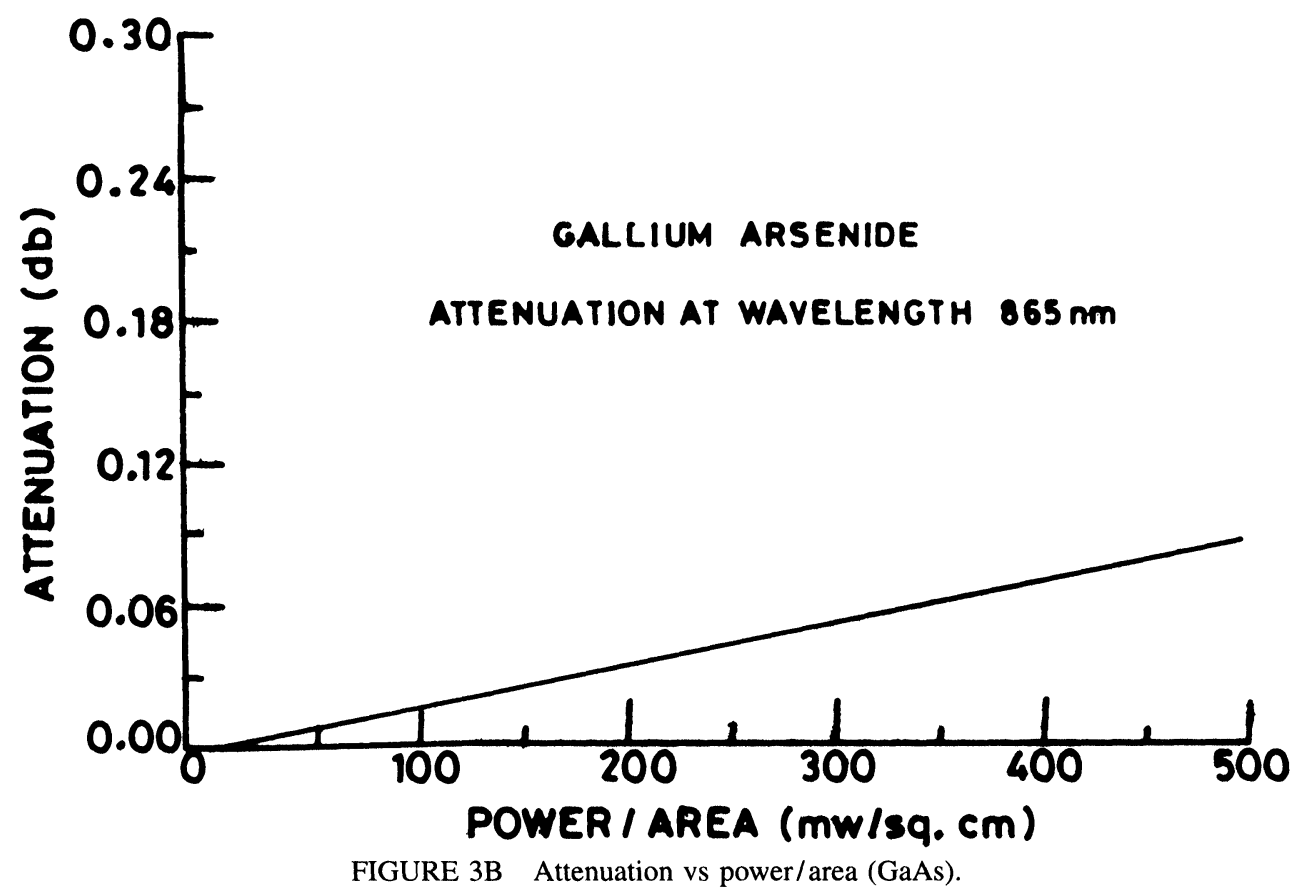

Theoretically, attenuation can be evaluated by calculating $\mathrm{S}$ parameters for the equivalent circuits. The attenuation obtained is:

Attenuation $(\mathrm{dB})=10 \log _{10}\left|\mathrm{~S}_{21}\right|^{2}$

where

$\mathrm{S}_{21}=\frac{2}{2+\mathrm{GZ}_{0}}$

G: photoconductance

$\mathrm{Z}_{0}$ : characteristics impedence of the microstripline

\section{DESIGN AND FABRICATION}

The design of various configurations in a coplanar waveguide/microstrip line using silicon/gallium arsenide substrate has been carried out using design equations given in [3]. Various parameters are given below: 


\begin{tabular}{lll} 
Parameter & $\mathrm{Si}$ & GaAs \\
\hline Er & 11.7 & 12.9 \\
Bandgap $\left(\mathrm{E}_{\mathrm{g}}\right)$ & $1.12 \mathrm{eV}$ & $1.43 \mathrm{eV}$ \\
$\lambda \mathrm{g}=\mathrm{hc} / \mathrm{Eg}$ & $1109 \mathrm{~nm}$ & $869 \mathrm{~nm}$ \\
$\mathrm{w} / \mathrm{h}$ & 0.8083 & 0.7275 \\
\hline
\end{tabular}

The penetration depth de, to which to photoconducting plasma is created, is given by

$\mathrm{d}_{\mathrm{e}}=\frac{\mathrm{L}_{\mathrm{a}}\left(1+\alpha \mathrm{L}_{\mathrm{a}}\right)+\mathrm{V}_{\mathrm{s}} \mathrm{t}}{\alpha\left(\mathrm{L}_{\mathrm{a}}+\mathrm{v}_{\mathrm{s}} \mathrm{t}\right)} * \frac{\left(\alpha \mathrm{L}_{\mathrm{a}}^{2}+\mathrm{v}_{\mathrm{s}} \mathrm{t}\right) \alpha \mathrm{L}_{\mathrm{a}} /\left(1-\alpha \mathrm{L}_{\mathrm{a}}\right)}{\left(\mathrm{L}_{\mathrm{a}}\left(\mathrm{L}_{\mathrm{a}}+\mathrm{v}_{\mathrm{s}} \mathrm{t}\right) \alpha \mathrm{L}_{\mathrm{a}} /\left(1-\alpha \mathrm{L}_{\mathrm{a}}\right)\right.}$

where

$\alpha$ : absorption coefficient

$\mathrm{L}_{\mathrm{a}}$ : ambi-polar diffusion length

$\mathrm{v}_{\mathrm{s}}$ : surface recombination velocity

t: excess carrier lifetime

The expression for $d_{e}$ shows that it is dependent on a, which in turn is a strong function of wavelength. This dependence of penetration depth on wavelength is used to decide the wavelength of the optical source. ${ }^{4-5}$

\section{EXPERIMENTAL RESULTS}

A plot of attenuation vs optical power is shown in Fig. 3A \& B and readings tabulated in Table 1 at wavelengths $632 \mathrm{~nm} \& 830 \mathrm{~nm}$.

TABLE 1

\begin{tabular}{rcc}
\hline Power/Area $(\mathrm{mW} / \mathrm{sq} \mathrm{cm})$ & $\begin{array}{l}\text { SILICON at } 632 \mathrm{~nm} \\
\text { Attenuation }(\mathrm{dB})\end{array}$ & $\begin{array}{c}\text { At } 830 \mathrm{~nm} \\
\text { Attenuation }(\mathrm{dB})\end{array}$ \\
\hline 0.00 & -0.0000 & -0.0000 \\
50.00 & 0.1338 & 0.1712 \\
100.00 & 0.2655 & 0.3390 \\
150.00 & 0.3953 & 0.5037 \\
200.00 & 0.5231 & 0.6653 \\
250.00 & 0.6491 & 0.8240 \\
300.00 & 0.7733 & 0.9798 \\
350.00 & 0.8958 & 1.1328 \\
400.00 & 1.0165 & 1.2832 \\
450.00 & 1.1356 & 1.4311 \\
500.00 & 1.2531 & 1.5765 \\
\hline
\end{tabular}


The following results are obtained:

(i) Source: Laser Diode with emission wavelength $830 \mathrm{~nm}$

Laser Diode bias current $=55 \mathrm{~mA}$

Detected microwave voltage $=38 \mathrm{mV}$; before attenuation (without illumination)

Detected microwave voltage $=37 \mathrm{mV}$; after attenuation (with illumination)

Attenuation $(\mathrm{dB})=10 \log (37 / 38)$

$$
=0.116 \mathrm{~dB}
$$

(ii) Source: He-Ne Laser with emission wavelength of $632 \mathrm{~nm}$

Laser Beam intensity at the gap $=400 \mathrm{~mW} / \mathrm{sq}$ om

Detected microwave voltage $=30 \mathrm{mV}$; before attenuation (without illumination)

Detected microwave voltage $=29.3 \mathrm{mV}$; after attenuation (with illumination)

Attenuation $(\mathrm{dB})=20 \log (29.3 / 30)$

$$
=0.1025 \mathrm{~dB}
$$

\section{CONCLUSIONS}

The attenuation obtained experimentally is less than that of the theorectical calculations due to various theoretical and experimental errors. Due to discrete values of the strip conductor width and substrate thickness available, the characteristic impedance of the microstripline is less than $50 \mathrm{ohms}$. The dimensions of the beam width of the laser and of the illuminated gap of the transmission line structure used could not be measured accurately. There is a possibility of better alignment of the optical source beam and the gap to be illuminated. The results, although not absolutely perfect, are considered encouraging.

\section{REFERENCES}

[1] J.S. Blakemore, "Characteristics of GaAs," J. Appl. Phys., Vol. 53, No. 10, October 1982.

[2] Walter Platte and Bernhard Sauerer, "Optically CW-Induced Losses in Semiconductor Coplaner Waveguide," IEEE Transaction on Microwave Theory and Technique, Vol. 37, No. 1, January 1989.

[3] K.C. Gupta, R. Garg and I.J. Bahl, Microstrip Lines and Slotlines. Dedham, MA: Artech House, 1979.

[4] Gerd Keiser, Optical Fiber Communication. McGraw Hill Book Company, 1989.

[5] Chi H. Lee, "Picosecond Optoelectronic Switching in GaAs," Applied Physics Letters, Vol. 30, No. 2, 15 January 1977. 

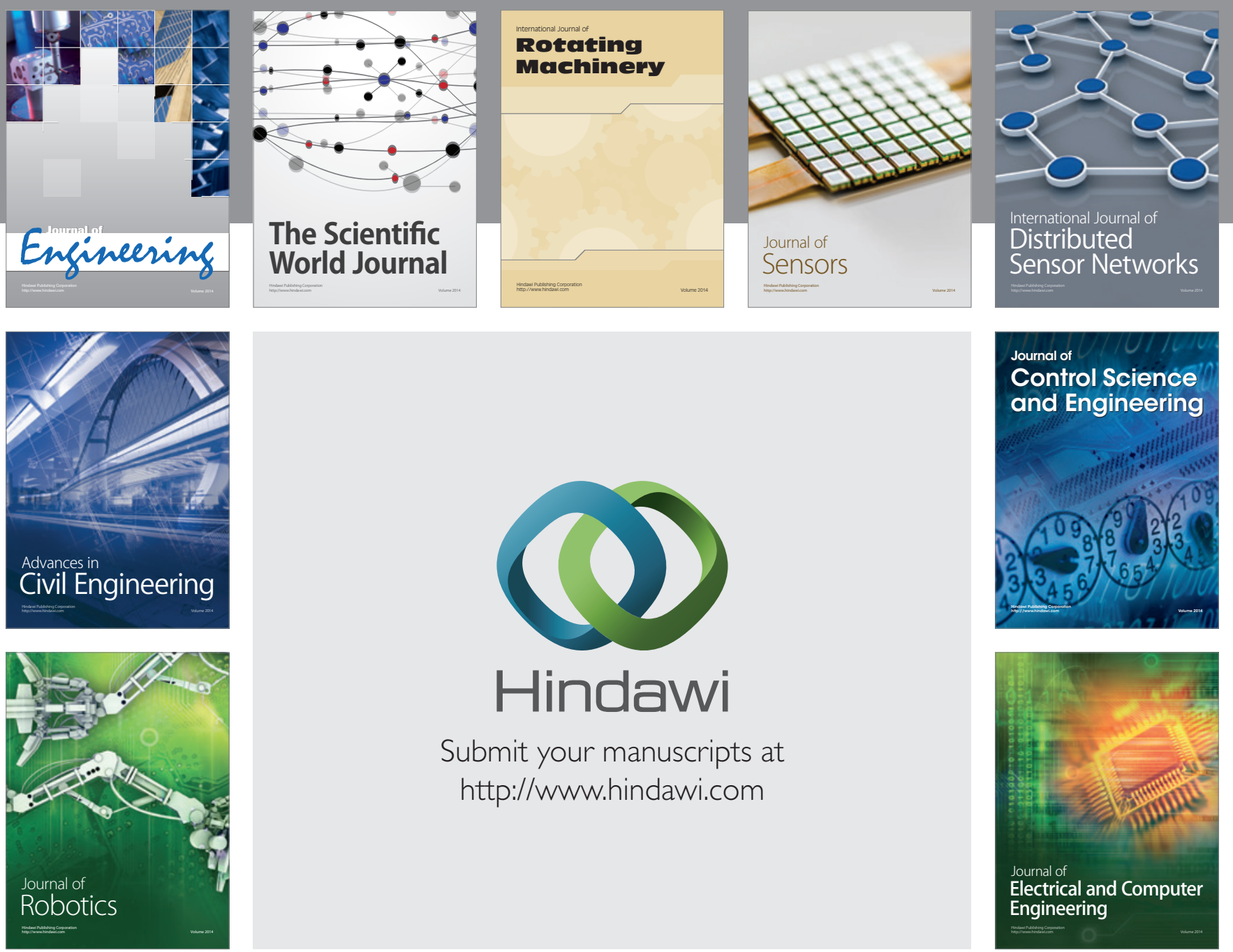

Submit your manuscripts at

http://www.hindawi.com
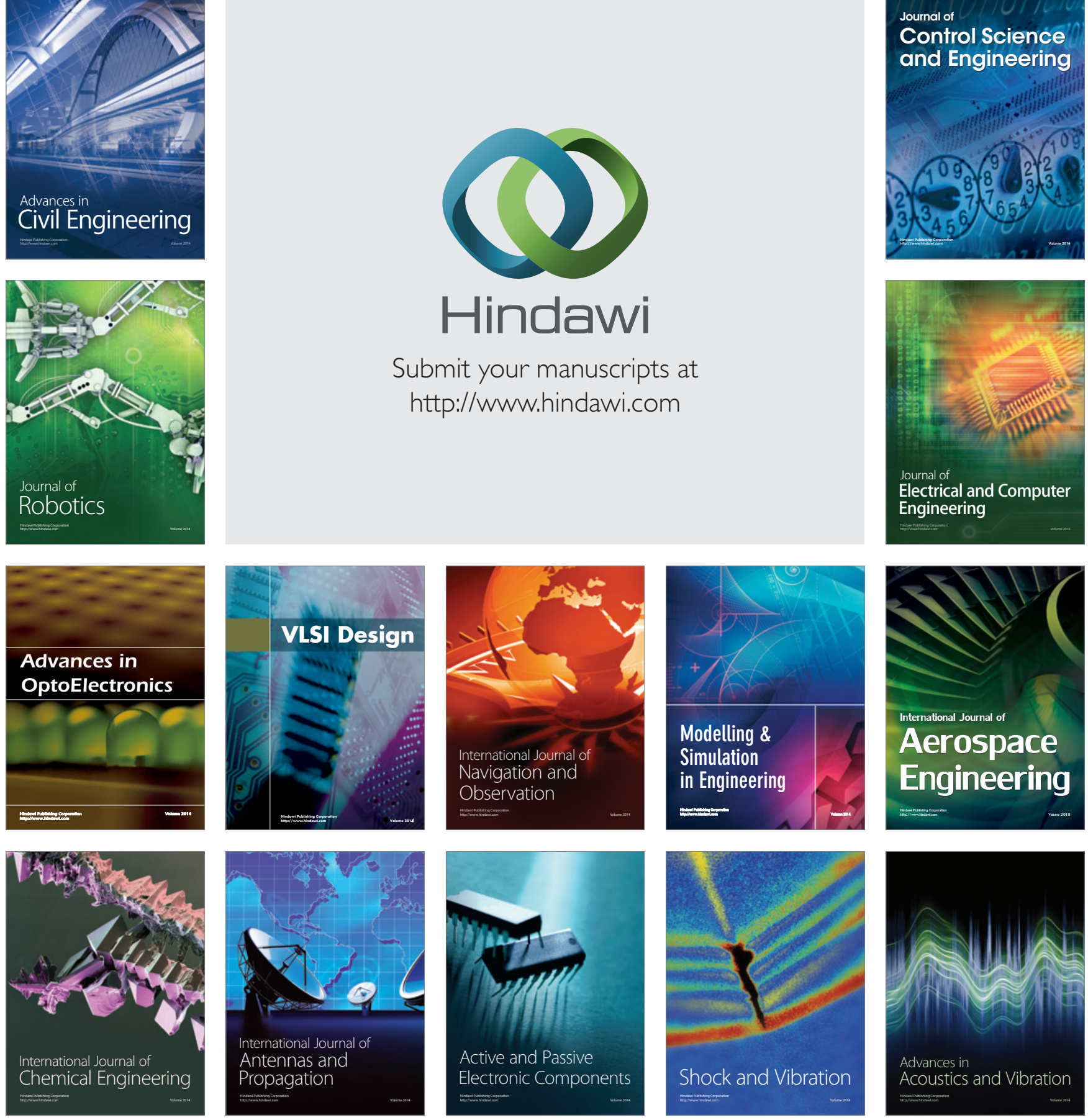